\title{
TELENOVELA, MELODRAMA E O SOFRIMENTO POR DROGADIÇÃO'
}

\section{SOAP OPERA, MELODRAMA AND SUFFERING IN DRUG ADDITION}

Mariana Almeida*

Leandro Rodrigues Lage*

\section{RESUMO:}

Com o melodrama como uma de suas principais bases de construção, a telenovela atua como espaço privilegiado de problematizações sociais do país, com frequente exploração de sujeitos em sofrimento a partir de valores morais, do apelo realista e das possibilidades da linguagem televisiva. Nesse contexto, a drogadição, com suas consequências internas e externas aos adictos, tem sido tema frequente dessas tramas desde a década de 1980. Partindo desse contexto, propomos uma reflexão sobre a relação intrínseca que há entre telenovela, melodrama e sofrimento associado às experiências de drogadição. Acreditamos que essa tríade apresenta peculiaridades que permitem uma compreensão mais nuançada dessas narrativas e do sofrimento que comunicam e produzem sentidos, mostrando-se mais elaboradas, complexas e em sintonia com mudanças e/ou permanências sensíveis, sociais e morais ocorridas ao longo da história da teledramaturgia.

\section{PALAVRAS-CHAVE:}

Telenovela, Sofrimento, Drogadição.

\section{ABSTRACT:}

Having the melodrama as one of its main foundations, the telenovela functions as a privileged space of social problematizations, exploring subjects in suffering based on moral values, realistic appeal, and the possibilities of television language. In this context, drug addiction has been a frequent theme of these plots since the 1980s, including its internal and external consequences to addicts. This study proposes a reflection on the intrinsic relationship between soap opera, melodrama, and suffering associated with the experiences of drug addiction. We believe that this triad presents peculiarities that allow a deeper understanding of these narratives and the suffering that communicate

* Doutoranda no Programa de Pós-Graduação em Comunicação Social, UFMG, Brasil. E-mail: marianalmeida13@ gmail.com q

** Docente da Faculdade de Comunicação e pesquisador do Programa de Pós-Graduação em Comunicação, Cultura e Amazônia, UFPA, Brasil. E-mail: leandrolage@ufpa.br 
and produce meanings, showing to be more elaborate, complex and in tune with social and moral changes and/or continuances that occurred throughout the history of the soap operas.

\section{KEYWORDS:}

Soap opera, Suffering, Drug addiction.

\section{INTRODUÇÃO}

Com aparência descuidada e adoentada, Larissa pesquisa roupas em uma loja quando se lembra do tempo em que era modelo, no auge de sua carreira e beleza, desfilando em passarelas. Enquanto se deixa abater com as memórias, é expulsa pelo vendedor e revolta-se com a situação. Derruba no chão itens das prateleiras e depara-se com um espelho: desde que passou a morar na rua e a entregar-se totalmente ao uso compulsivo do crack, aquela era a primeira vez que ela enfrentava sua própria imagem. A personagem, que sustentava uma elevada autoestima e um orgulho pela sua aparência e profissão, choca-se com o que vê. Em primeiro plano, Larissa chora desesperada enquanto toca em si mesma. Na trilha musical que acompanha a cena, o som de violinos e de um piano acentuam a dramaticidade. Larissa sai da loja consternada. Em slow motion, o plano seguinte a exibe caminhando entristecida pela cidade. Cortes suaves com fades em branco enfatizam suas expressões aflitas, que dão início, a partir de então, a um processo de tomada de consciência do seu estado e da necessidade de ajuda para livrar-se do vício.

A cena de Larissa, personagem interpretada pela atriz Grazi Massafera na telenovela Verdades Secretas (2015) exibida pela Rede Globo, traz à tona um conjunto de problemas relacionados à dramatização melodramática e à moralização do sofrimento associado à drogadição na ficção televisiva brasileira. O pano de fundo desses problemas é o reconhecimento do papel cultural da teledramaturgia no país na consolidação tanto do próprio hábito de ver televisão, quanto dos parâmetros morais que balizam certos modos de narrar problemas sociais. Ao traçarmos um panorama histórico de personagens dependentes químicos e seus papéis nas telenovelas brasileiras, percebemos a prevalência de uma retórica realista, moralista e melodramática das experiências de sofrimento. Essa síntese é reveladora da capacidade que a TV possui para explorar tensões e conflitos sociais em suas gramáticas morais específicas, designando sofrimentos justos ou injustos, discriminando vítimas e vilões e conformando, a partir dos apelos 
realistas e emotivos, o destino de personagens e das histórias dentro de um horizonte moral circunscrito.

Este trabalho é parte dos resultados de pesquisa em nível de mestrado e nosso percurso, realizado a partir de uma reflexão e análise mais geral sobre o assunto, sem nos determos tanto em personagens específicos da ficção, inicia-se com uma breve discussão sobre a relação histórica que a telenovela brasileira vem construindo com a realidade e o contexto social vigentes ao longo das últimas décadas, reforçando um papel de problematização do país. Em seguida, abordamos o vínculo intrínseco e peculiar que o formato telenovela e o gênero melodrama estabeleceram no continente latino-americano enquanto modos de expressão, reconhecimento e moralização, para, então, chegarmos mais especificamente à questão sobre a drogadição e o sofrimento nessas narrativas melodramáticas, buscando compreender como essa relação é construída.

\section{TELENOVELA BRASILEIRA: DO APELO REALISTA À MORALIZAÇÃO DOS PROBLEMAS SOCIAIS}

Em seus estudos sobre a ficção televisiva, Martín-Barbero e Rey (2001) indicam o papel da televisão no processo de transição da ruralidade para a urbanização na América Latina durante meados do século XX. Para eles, "se as novas condições de vida na cidade exigem a reinvenção de laços sociais e culturais, são as redes audiovisuais que instauram, a partir de sua própria lógica, as novas figuras dos intercâmbios urbanos" (MARTÍN-BARBERO; REY, 2001, p. 52). Em meio a esse contexto, a teledramaturgia foi essencial para a consolidação do hábito de ver TV no Brasil, incorporando aspectos marcantes da cultura e constituindo-se em uma hibridização de linguagens e narrativas.

Para esses autores, “a televisão aparece como um espaço de cruzamentos estratégicos com certas tradições culturais de cada país: orais, gestuais, escritas, teatrais, cinematográficas, novelescas etc." (MARTíN-BARBERO; REY, 2001, p. 41). No caso do Brasil, a construção da teledramaturgia se deu a partir do rádio, com as radionovelas, que, por sua vez, eram marcadas pelas construções melodramáticas inspiradas nos folhetins dos jornais impressos, o primeiro produto de cultura massiva a circular periodicamente no espaço urbano. Todas essas características atuaram na construção da telenovela tal como a conhecemos hoje: a escrita em capítulos, o apelo sentimental, a predominância do romance romântico, os enredos e personagens maniqueístas, a moralização etc. (PALLOTTINI, 2012, p. 50). 
Inserida em meio à modernidade do pós-guerra, em que o espaço destinado às mulheres voltou a ser o doméstico, a televisão e, especificamente no caso brasileiro, a novela foi responsável por diluir os limites entre público e privado, real e ficcional, pessoa e personagem, dando ênfase à vida cotidiana orientada pela família construída segundo valores burgueses hegemônicos. Principalmente a partir do final da década de 1960, as novelas passaram a investir na relação com o "mundo exterior", com constantes referências à temporalidade e à realidade contemporâneas por meio de apropriação de elementos da linguagem jornalística (HAMBURGER, 2007; LOPES, 2009). Nessa guinada realística, ao incorporar nas tramas a atualidade e a urgência dos fatos noticiosos relacionados a dramas morais, as novelas tornam-se mediadoras entre as experiências da vida pública e da vida privada dos telespectadores.

Ao discutir sobre o apelo realista que atravessa e orienta essas narrativas audiovisuais, Feldman (2008) destaca o papel que elas têm no "reengajamento" e na "reintegração" dos sujeitos à realidade, em que quanto mais a vida cotidiana é "roteirizada, ficcionalizada e virtualizada", mais há o anseio pela experiência do real e do choque que ela é capaz de provocar - mesmo na televisão, em que as imagens são mais roteirizadas e controladas por diversas instâncias de poder e, portanto, com lógicas econômica, estética e moral diferentes das imagens amadoras ou de produção doméstica.

Essa realidade mediada e dramatizada é composta por "códigos estéticos e suportes audiovisuais cujas fronteiras também estariam se tornando indistintas” (FELDMAN, 2008, p. 62). Nesse ponto, a autora destaca a atuação da Rede Globo que, na corrida pela manutenção de sua hegemonia simbólica e comercial na produção e no controle do imaginário nacional, tem incorporado e desenvolvido cada vez mais intensos e eficazes efeitos de real como maneira de legitimar, por meio do apelo realista, a encenação melodramática, a exemplo dos depoimentos de pessoas reais anônimas incorporados às telenovelas Páginas da Vida (2006) e O Clone (2001) e até mesmo em séries mais recentes, como Segunda Chamada (2019).

A partir da década de 1990, essas referências à vida real passaram a assumir o papel de intervenção no cotidiano dos telespectadores, como em O Rei do Gado (1996), que possibilitou visibilidade política aos dramas e conflitos da reforma agrária e dos trabalhadores sem-terra, ou como em Explode Coração (1995), na qual a emissora, atendendo à demanda do próprio público, assumiu o papel de investigadora para reencontrar crianças desaparecidas e devolvê-las às mães, tornando-se mais eficiente que a polícia 
ou o Poder Judiciário (HAMBURGER, 2007; LOPES, 2009). Em 2012, a telenovela Cheias de Charme, exibida no horário das $19 \mathrm{~h}$ na Rede Globo, contribuiu para o debate sobre as regulamentação trabalhista do emprego doméstico por meio da PEC 66/2012, conhecida como PEC das domésticas, que naquele ano estava em discussão no Congresso Nacional e foi aprovada logo em seguida da exibição da telenovela. Foi a primeira vez no Brasil em que a figura da empregada doméstica alçou o posto de protagonismo em uma telenovela, com uma trajetória que foi da humilhação e precarização nas relações de trabalho ao sucesso e estrelato por meio da música.

No Brasil, um país marcado pela desigualdade e pelos graves e históricos contrastes sociais, a televisão tem sido historicamente responsável pela ampla disseminação e partilha de códigos (FRANÇA, 2006) que possibilitam, desde o seu início, a construção de uma ideia de nação, de pertencimento e de reconhecimento. Ao mesmo tempo, a TV incorpora facilmente em suas narrativas, tanto pelo crescente apelo realista quanto pela estreita ligação que preserva com a vida social e cotidiana, os conflitos, os sofrimentos e as lutas sociais. A televisão configura-se, assim, como espaço privilegiado de problematizações do Brasil (HAMBURGER, 2011; LOPES, 2003), trazendo à discussão pública temáticas sensíveis, controversas e socialmente relevantes como demandas legitimadas pelos grupos de receptores, mas não sem antes ressignificá-las em função do discurso social hegemônico (MARTíN-BARBERO; MUÑOZ, 1992). Nesse sentido, a telenovela, com sua linguagem marcadamente melodramática, é um dos produtos televisivos mais representativos do campo de possibilidades aberto pela TV para um horizonte de transformação social (BACCEGA, 2003; LOPES, 2003; MOTTER, 2002).

O sofrimento, portanto, faz parte desse investimento televisivo na construção de apelos realistas, de abordagens melodramáticas e, consequentemente, na moralização do espectador. Para além da espetacularização do sofrimento, autores como Boltanski (2004) e Chouliaraki $(2009,2013)$ chamam a atenção para o lugar ambíguo do espectador televisivo: instado a ocupar a posição de sujeito moral e convidado a agir a respeito do sofrimento do outro, o espectador vive a tensão entre a impressão de testemunhar e a impotência de não poder agir, em função do distanciamento que o separa do sofredor. Ainda que as telenovelas sejam narrativas ficcionais, essa aproximação do cotidiano das cidades brasileiras pela via de testemunhos e de histórias "baseadas em fatos reais" também chama a atenção para a realidade dos sofrimentos televisionados segundo um ponto de vista moralizante. 
Conforme argumenta Chouliaraki (2009), a piedade com os personagens sofredores não é necessariamente um sentimento empático, mas sim um princípio constituído "a fim de relacionar sujeitos sociais, a partir daquilo que um espectador é capaz de sentir por uma vítima" (p. 179), de maneira a se estabelecer o que Boltanski chama de relação generalizada com o outro. Ou seja, mais do que transformar os sofrimentos que afetam a população brasileira em temática e em personagens dramáticos, as telenovelas também instituem uma forma de ser espectador ancorada nessas realidades sociais, encenadas, por sua vez, segundo rigorosas estratégias realistas e melodramáticas, de acordo com parâmetros morais que definem os sofrimentos justos e/ou injustos, as possibilidades de perdão e de redenção, as vítimas legítimas e/ou ilegítimas, os perpetradores responsáveis pelo sofrimento alheio, as lições a serem aprendidas etc.

Como exemplo, podemos citar a personagem Raquel, de Mulheres Apaixonadas (2003), agredida pelo marido por diversas vezes com uma raquete de tênis. A trama recebeu grande repercussão por parte do público por denunciar a realidade da violência doméstica e a dificuldade em denunciar. Ao final da trama, após levar o caso à polícia, a personagem vítima reestabelece sua vida normal quando seu algoz morre em um grave acidente. Se, por um lado, há uma longa lista de personagens enredados como vítimas cujo sofrimento é legitimado como injusto, há também um extenso número de personagens vilões cujo papel é performar o avesso de uma moralidade, geralmente marcados por um fim trágico, punitivo ou redentor.

Antes de passarmos mais diretamente à drogadição e aos sofrimentos dela decorrentes tais como narrados pelas telenovelas brasileiras nas últimas quatro décadas, cumpre indagarmos sobre os cruzamentos entre o melodrama e a telenovela no contexto da América Latina, e especialmente do Brasil, cotejados aos aspectos da linguagem da telenovela que possibilitam a construção de tramas e personagens envolvidos em temas e dramas sociais específicos.

\section{MELODRAMA E TELENOVELA: ENCONTRO DE GÊNEROS NA AMÉRICA LATINA}

$\mathrm{Na}$ construção histórica das telenovelas, o melodrama sempre esteve presente como componente dessas narrativas. Popularizado nos palcos teatrais, o gênero tem sua origem associada à ópera que, durante a ascensão da Era Moderna entre os séculos XVIII e XIX, passa a ser encenada nos teatros francês e inglês (XAVIER, 2000) em um momento 
no qual o teatro deixa de ser uma exclusividade das classes privilegiadas e começa a ocupar espaços públicos e populares nas grandes cidades (ALMEIDA, 2019).

Ao melodrama não era permitida a utilização de diálogos e canções para evitar um “empobrecimento" dos teatros oficiais. Por isso, ele constrói sua dramaticidade a partir de gestos, expressões corporais, efeitos visuais e sonoros, sem deixar espaço para sutilezas, lirismos, experimentalismos e/ou ambiguidades, em suma, "uma linguagem simples e de fácil apreensão, destinada a um público amplo e diverso, em grande parte desacostumado com arte tradicional e sem repertório prévio para consumir produtos mais complexos” (ALMEIDA, 2019, p. 5). No período da Revolução Francesa, o melodrama permitiu às classes populares encenar suas emoções, paixões e moralidades. "Antes de ser um meio de propaganda, o melodrama será o espelho de uma consciência coletiva” (MARTÍN-BARBERO, 2009, p. 164).

Por ter sua origem em uma encenação não-falada, o melodrama pode ser também, mas não essencialmente, caracterizado pelo excesso de gestos, músicas, efeitos e uma fisionomia peculiar dos personagens que possibilitam a tradução da moral de valores e contravalores éticos a partir da aparência (MARTíN-BARBERO, 2009). As palavras, portanto, importam menos que os jogos mecânicos e óticos.

Tudo no melodrama tende ao esbanjamento. Desde uma encenação que exagera os contrastes visuais e sonoros até uma estrutura dramática e uma atuação que exibem descarada e efetivamente os sentimentos, exigindo o tempo todo do público uma resposta em risadas, em lágrimas, suores e tremores (MARTíN-BARBERO, 2009, p. 171).

Os gêneros atuam, segundo Martín-Barbero (2009, p. 301), como "mediação fundamental entre as lógicas do sistema produtivo e as do sistema de consumo, entre a do formato e a dos modos de ler, dos usos", pois são mecanismos capazes de ativar a competência cultural e de dar conta das diferenças sociais pelas quais são atravessados. O gênero, especialmente o fictício, diz o autor, é a unidade mínima do conteúdo da comunicação de massa, uma estratégia de comunicabilidade e a chave para a leitura e análise dos textos televisivos (MARTíN-BARBERO, 2009). É nesse sentido que o melodrama serve como eixo balizador em torno do qual é possível compreender a produção de telenovelas a partir de sua relação com as culturas popular e midiática, o que justifica boa parte de sua permanência, adaptação aos meios massivos e popularidade:

Gênero permite a Martín-Barbero, portanto, reconhecer, a partir do melodrama, o modo como o massivo opera de dentro do popular ou o modo como a cultura midiática ao mesmo 
tempo em que se impõe ao povo, através das corporações midiáticas com suas lógicas de produção, também deriva de experiências, gostos e costumes populares que configuram as lógicas de consumo e usos (GOMES, 2011, p. 124).

O melodrama constitui-se, então, como um gênero encenado para fazer rir e chorar, assim como para reforçar valores morais a partir de códigos, linguagens e apelos afetivos assentados em matrizes culturais comuns. É o gênero que investe no pranto, “inspirando a piedade e o temor necessários para atuar como catarse legítima de tais emoções” (OROZ, 1999) e conquistar o público espectador com narrativas compostas por convencionalismos sociais, definindo, assim, a relação entre gosto popular e moral social.

Essa característica moralizante, em que os conflitos entre o bem e o mal são mostrados muitas vezes sem nuances, advém de uma vocação e necessidade de oferecer matrizes sólidas diante de uma sociedade instável. Para Xavier (2000), por ser flexível e capaz de adaptar-se rapidamente ao contexto histórico e social vigente, o "melodrama formaliza um imaginário que busca sempre dar corpo à moral, torná-la visível, quando esta parece ter perdido os seus alicerces" na modernidade (XAVIER, 2000, p. 85). Com a valorização de razões sentimentais, principalmente no âmbito dos laços familiares e os segredos que ali convivem, o melodrama opera sobre o eixo da moralidade e sua legitimação, em que a perseguição da virtude desempenha papel fundamental ao ganhar visibilidade e validação (ALMEIDA, 2018). Ao propor resoluções mágicas e pacificadas para os conflitos e sofrimentos vividos pelos personagens, com lições de moral associadas a sistemas de valores sedimentados socialmente, o melodrama contempla tanto a necessidade de representação e reconhecimento dos povos quanto a lógica hegemônica de produção massiva ao não propor e/ou não estimular soluções que desestabilizem a ordem estabelecida (MARTíN-BARBERO; MUÑOZ, 1992).

Devido à capacidade de cativar públicos a partir de narrativas e dramas morais com apelos visuais e sonoros e de se adaptar facilmente aos objetos modernos, o melodrama encontra em produtos como cinema e televisão ambientes propícios para sua permanência, evolução e popularização. Os países da América Latina, dando continuidade à sua cultura oralizada em uma sociedade desigual e repleta de contrastes, têm no melodrama um modelo propício para a manifestação de tensões e conflitos sociais que marcam a realidade do povo. 0 gênero encontrou na América Latina seu terreno mais fértil de popularização, fortificação e crescimento, proporcionado pelas matrizes culturais de formação do continente (MARTíN-BARBERO, 1987) marcadas pela oralidade, 
por crenças e rituais; pela necessidade de reconhecimento social, cultural e identitário de povos atacados, negados e apagados em meio à modernidade. "E a partir disso, melodramatizando tudo, vingam-se a seu modo, secretamente, da abstração imposta pela mercantilização da vida e despossessão cultural" (MARTÍN-BARBERO; MUÑOZ, 1992, p. 29). Telenovelas de sucesso, marcadas até hoje na memória do telespectador, reafirmam o melodrama como eixo fundamental na construção da teledramaturgia brasileira.

Ao longo da história, a presença do melodrama nas narrativas telenovelísticas brasileiras foi sendo modificada, seguindo a característica do próprio gênero de adaptação aos novos contextos. Se antes os dramas e romances eram ambientados em épocas e espaços distantes e exóticos, sem conexão direta com aspectos da realidade e sociedade brasileiras, a partir da década de 1960, com a novela Beto Rockfeller (1968), essas histórias mudam e tornam-se mais realistas, reconhecíveis, vividas por personagens dentro de um mundo comum (PALLOTTINI, 2012). Essa necessidade de apelo realista vem acompanhada do regime de visualidade e sonoridade que convoca o telespectador a acompanhar, a se emocionar e a se comover com o sofrimento vivido por esses personagens em seus dramas e conflitos familiares e sociais, acionados pela construção de apelos compassivos e pela construção de atmosferas emotivas, como na cena da personagem Larissa que descrevemos no início do trabalho.

\section{A DROGADIÇÃO E O SOFRIMENTO FICTÍCIO TELEVISIONADO}

Se os conflitos amorosos e outros temas - como a vingança e os dramas entre pais e filhos - estão presentes desde os primeiros anos da telenovela no Brasil, o mesmo não se pode dizer a respeito da dependência química. 0 alcoolismo e o uso de entorpecentes classificados como drogas ilícitas, a exemplo da cocaína e do crack, tornaram-se questões social, moral, legal e de saúde pública no país a partir das décadas de 1960 e $1970^{2}$. Ou seja, há décadas o Brasil enfrenta conflitos relacionados à dependência química de álcool e de drogas ilícitas e isso tem sido tema frequente de discussão pública e privada nos grandes centros urbanos do país.

Nesse contexto, as telenovelas vêm incorporando a temática às suas tramas, ampliando a visibilidade da questão e possibilitando mais debates e possíveis soluções. Ainda que o alcoolismo tenha surgido pela primeira vez em telenovelas no início da década de 1980, foi em 1988, com a personagem Helena Roitman (Renata Sorrah), de Vale Tudo, que o tema se tornou popular na teledramaturgia brasileira. Em 1997, a doença do 
alcoolismo atinge grande repercussão com o personagem Orestes (Paulo José) de Por Amor (CAMPOS, 2004), sendo cada vez mais frequente nos folhetins a partir de então.

Em relação à dependência de drogas ilícitas, é apenas no início dos anos 2000, com os personagens Mel (Débora Falabella), Lobato (Osmar Prado) e Nando (Thiago Fragoso), de $O$ Clone (2001), que a questão ganha maior projeção, acompanhando o próprio aumento na incidência de consumo no país. A narrativa chegou a ser premiada pelo Federal Bureau of Investigation (FBI) e pelo Drug Enforcement Administration (DEA), órgãos norte-americanos que atuam no combate ao tráfico de drogas, pelo viés proibicionista com o qual a telenovela retratou a questão (assim como outras também o fazem), sendo legitimada pelas instâncias de poder que regulam políticas antidrogas. Além disso, O Clone também foi apontada como responsável pelo aumento na procura por ajuda e tratamento em instituições como Narcóticos Anônimos e Alcoólicos Anônimos (CAMPOS, 2004).

Outras duas personagens que merecem destaque pela repercussão que conquistaram na audiência são a Santana (Vera Holtz), de Mulheres Apaixonadas (2003), uma professora de ensino médio alcoólatra que protagoniza cenas históricas, como a em que é jogada bêbada em uma piscina na frente de seus alunos e a que tenta beber perfume durante uma crise de abstinência; e Larissa (Grazi Massafera), de Verdades Secretas (2015), uma modelo e prostituta de luxo que se tornou a primeira personagem em telenovela viciada em crack, denunciando a realidade da cracolândia em São Paulo e nos demais centros urbanos do país. Por sua atuação, a atriz foi indicada ao prêmio Emmy Internacional.

Abaixo, sistematizamos em um quadro a partir de um levantamento desenvolvido manualmente durante a pesquisa, os personagens dependentes químicos (também chamados de toxicodependentes) de telenovelas brasileiras desde a década de 1980 até o ano de $2020^{3}$. Pelo levantamento, podemos observar que, especificamente em telenovelas da Rede Globo - maior produtora do gênero -, a temática da dependência química aparece, prioritariamente, em novelas exibidas na faixa das $21 \mathrm{~h}$, dedicada aos dramas e conflitos sociais e morais mais densos de acordo com a grade de programação. A exceção é de Verdades Secretas, exibida na faixa das 23h, e Coração de Estudante, exibida na faixa das $18 \mathrm{~h}$.

Também constatamos que não há grande distinção quantitativa de gênero masculino ou feminino, sendo, até hoje, somente estes dois gêneros representados nas novelas no 
que diz respeito à drogadição. Há uma equiparação numérica entre homens e mulheres que sofrem com a dependência química. No entanto, os modos de abordagem diferenciam-se, o que chama a atenção para o fato de que a maior parte dos personagens adictos que se tornaram populares e marcantes na memória da audiência é formada por mulheres (a exemplo de Heleninha, Mel, Santana e Larissa).

Quadro 1: Personagens dependentes químicos em telenovelas brasileiras

\begin{tabular}{|c|c|c|c|c|c|}
\hline Personagem & Ator/Atriz & Telenovela & Ano & Emissora & $\begin{array}{l}\text { Tipo de toxico- } \\
\text { dependência }\end{array}$ \\
\hline Doca & André de Biase & Os Adolescentes & 1981 & Band & Não especificada \\
\hline Helena & Renata Sorrah & Vale Tudo & 1988 & Globo & Álcool \\
\hline Orestes & Paulo José & Por Amor & 1997 & Globo & Álcool \\
\hline Lobato & Osmar Prado & O Clone & 2001 & Globo & Álcool e cocaína \\
\hline Nando & Thiago Fragoso & O Clone & 2001 & Globo & Cocaína \\
\hline Mel & Débora Falabella & O Clone & 2001 & Globo & Álcool e cocaína \\
\hline Regininha & Viviane Victorette & O Clone & 2001 & Globo & Cocaína \\
\hline Mariana & Carolina Kasting & Coração de Estudante & 2002 & Globo & Álcool \\
\hline Cristiano & Alexandre Borges & Celebridade & 2003 & Globo & Álcool \\
\hline Santana & Vera Holtz & Mulheres Apaixonadas & 2003 & Globo & Álcool \\
\hline Rudi & Petrônio Gontijo & Poder Paralelo & 2009 & Record & Não especificada \\
\hline Danilo & Cauã Reymond & Passione & 2010 & Globo & Anabolizantes \\
\hline Renata & Bárbara Paz & Viver a Vida & 2010 & Globo & Álcool \\
\hline Larissa & Grazi Massafera & Verdades Secretas & 2015 & Globo & Crack \\
\hline Bruno & João Vitor Silva & Verdades Secretas & 2015 & Globo & Cocaína \\
\hline Fábia & Eva Wilma & Verdades Secretas & 2015 & Globo & Álcool \\
\hline Beth & Glória Pires & O Outro Lado do Paraíso & 2017 & Globo & Álcool \\
\hline Narciso & Osmar Silveira & O Segundo Sol & 2018 & Globo & Crack \\
\hline Manuela & Luiza Arraes & O Segundo Sol & 2018 & Globo & Não especificada \\
\hline Abdias & Felipe Titto & A Dona do Pedaço & 2019 & Globo & Álcool \\
\hline Lígia & Malu Galli & Amor de Mãe & 2020 & Globo & Álcool \\
\hline
\end{tabular}

Fonte: elaborado pelos autores.

Pelo quadro, percebemos que as abordagens da dependência química em telenovelas que receberam certo destaque nas tramas ainda estão restritas a personagens brancos e pertencentes às classes média e alta, excluindo do processo a incidência do problema em estratos mais pobres da sociedade e em outros grupos étnico-raciais. A abordagem 
moralizante da drogadição, cujo proibicionismo se ancora em uma percepção clínica do problema, privilegia não apenas o depauperamento físico e emocional dos personagens adictos, mas também seu desmoronamento social completo nas esferas econômica, profissional, familiar etc.

Diante da baixa representatividade das classes $D$ e $E$ e de outras minorias na tematização do problema da drogadição, os enredos telenovelísticos enfatizam os impactos do uso compulsivo de entorpecentes em núcleos familiares relativamente estáveis e hegemônicos. A exemplo de Helena, a primeira personagem mulher alcoólatra, que é rica, filha da vilã Odete Roitman e uma artista reconhecida que busca tratamento com um psiquiatra para superar o vício, os traumas do passado e o relacionamento complicado que tem com a mãe. Ao ter uma recaída, Helena passa por constrangimentos públicos, abandona a carreira, é novamente internada, perde o marido e tem como única solução possível de retorno a uma vida saudável o encontro de um novo amor.

Destacamos também a oscilação entre protagonismo e coadjuvância que os personagens sofreram a partir da abordagem da dependência química. De maneira geral, o matiz melodramático da construção de certos personagens faz com que figuras coadjuvantes como a de Mel ( $O$ Clone) e de Larissa (Verdades Secretas) ganhem mais espaço e destaque nas tramas. Ambas acabaram protagonizando capítulos decisivos e cenas memoráveis em suas trajetórias. A aceitação de uma retórica realista do sofrimento associado à drogadição por parte do público é, sem dúvida, um indício do sucesso da fórmula: apelo realista, melodrama e drogadição em conjunto.

As peculiaridades do sofrimento experenciado por dependentes químicos nas telenovelas desencadeiam muitas vezes o aumento de visibilidade desses personagens, que se tornam centro das atenções dessas narrativas, que passam a ocupar o núcleo gravitacional das histórias (LAGE, 2017), ganhando mais espaço e sendo legitimadas pela notoriedade que recebem dentro e fora da tela, o que colabora para o sucesso de audiência dessas telenovelas e as marcam no imaginário dos telespectadores de modo a estimular a criação de novas histórias envolvendo a drogadição. Essas trajetórias melodramáticas de sofrimento conservam um padrão de relação com a droga: quando experimentam a primeira vez ou quando voltam a consumir mesmo sem poder; quando atingem o auge/ limite de degradação física, moral e social por conta do consumo extremo; e quando tomam consciência de si suficiente para impulsionar a busca por ajuda. 
Por outro lado, quando não houve um investimento dramático e/ou realista mais marcante, personagens coadjuvantes, como Danilo (Passione) e Renata (Viver a Vida), perderam espaço e destaque ao longo das novelas. Há ainda o caso de personagens em que a dependência química não era o ponto central de sua construção dramática, sendo um tema de segundo plano a receber relevância apenas em momentos específicos da telenovela. É o caso da personagem Beth (O Outro Lado do Paraíso), protagonista da novela que tinha o alcoolismo como pano de fundo de sua construção dramática. No caso dela, o alcoolismo foi relevante e central apenas no momento em que foi impedida de doar seu próprio rim para salvar a vida de uma das filhas; ou, ainda, o caso de Lígia (Amor de Mãe), em que o alcoolismo emerge na segunda metade da trama quando a personagem passa a sofrer com o luto da perda do único filho

No entanto, o que todos esses personagens adictos têm em comum é o sofrimento intenso causado pelo vício, que atinge consequências limites de degradação física, moral e/ou social - o personagem Cristiano, de Celebridade, chega a dormir bêbado na calçada e é ajudado pelo próprio filho menor de idade; Nando, de $O$ Clone, passa a roubar a própria mãe para comprar cocaína e é expulso de casa. Em seguida, há a busca por ajuda, tratamento e cura em algum momento da trama. Seja por via dos Alcoólicos Anônimos - o mais comum -, seja por clínicas de reabilitação, pela salvação religiosa, pela atuação das famílias ou dos Narcóticos Anônimos etc., o destino da maioria dos personagens culmina com a recuperação de uma vida física e socialmente saudável, em que se reconstroem os laços sociais e afetivos que foram perdidos ou prejudicados ao longo de suas trajetórias nas telenovelas.

0 personagem Orestes, por exemplo, passa a frequentar reuniões dos Alcoólicos Anônimos no último capítulo de Por Amor (1997), depois de reestabelecer o bem-estar e a harmonia na relação com suas duas filhas. A pedagogia moral é sempre a da valorização de uma vida longe de vícios, da importância de procurar ajuda (especializada, religiosa, da família e/ou amigos) para superar tais dificuldades e a da possibilidade de iniciar uma nova vida sem álcool e drogas.

Nota-se, por exemplo, que até hoje nenhuma telenovela abordou de forma central o debate em torno da legalização das drogas, como a maconha - que já é realidade em alguns países latino-americanos -, a relação da legalização com o tráfico de drogas sem incorrer num investimento dramático em torno da violência, com as milícias nos grandes centros urbanos ou mesmo a restrição legal de publicidade e uso do álcool, assim 
como ocorreu com o cigarro. O tema da drogadição em telenovelas, a exemplo da trajetória dos personagens sistematizados na tabela, ainda é construído em torno da proibição total e a partir de um pano de fundo moralizador. Não há nenhum caso em que os personagens usuários consigam levar uma vida social com o uso de entorpecentes sem que essa experiência esteja associada a uma degradação completa e/ou com atitudes moralmente questionáveis do personagem.

\section{CONSIDERAÇÕES FINAIS: O SOFRIMENTO MELODRAMÁTICO}

Ao comunicar em gestos, expressões, falas e efeitos visuais e sonoros suas necessidades - das mais básicas às mais abstratas -, seus desejos, suas angústias, suas revoltas diante das injustiças e suas buscas por uma vida feliz, o melodrama encontra na retórica do sofrimento um tipo de reconhecimento de certa forma pedagógico do padecimento do outro e da finitude humana (BIONDI, 2011), um modo fértil de tentar convocar, engajar e integrar o público, inspirando a piedade e o apelo compassivo diante dos dramas físicos, morais e sociais vividos pelos personagens e possibilitando aos espectadores uma espécie de prazer aliviante de testemunhar um sofrimento que poderia ser com eles, mas não é. Qualquer sofrimento, naquele instante, está suspenso ou atenuado pela experiência à distância, pela contemplação dos outros desafortunados e pelo olhar daqueles que não experimentam ou compartilham diretamente o sofrimento e que podem ser, portanto, ao menos naquele momento, considerados como pessoas de sorte (BOLTANSKI, 2004).

“Isto é, o caráter lacrimogêneo associado ao melodrama é baseado em uma piedade que busca gerar prazer através da contemplação do sofrimento dos protagonistas" (APREA, 2011, tradução nossa). Trata-se, portanto, de um regime de espectatorialidade marcado por um prazer voyeurístico contraditório, que convoca o espectador distante e é potencializado pelas construções de linguagem e imagem articuladas a partir de recursos tecnológicos disponíveis que produzem significados sobre o sofrimento capazes de propor modos específicos de envolvimento da audiência com os sofredores, de moralizar o espectador e de fazê-lo estabelecer relações emocionais com o que se vê (CHOULIARAKI, 2008; LAGE, 2016).

$\mathrm{Na}$ corrente de estudos sobre os modos de sofrimento midiatizados, o do tipo melodramático e televisionado reserva especial atenção por conta do "desenvolvimento de regimes de imagens e textualidades ancorados no espetáculo da dor e do sofrimento 
do outro vulnerável” (LAGE, 2017, p. 656). Não à toa, essas vítimas sofredoras que compõem as narrativas televisivas ganham significativa notoriedade - que resulta em legitimidade -, a partir de uma construção sentimentalista e instrumentalizada que transforma o sofredor em motivo de lamentação, enquanto o espectador é perturbado e compelido a se emocionar. Especialmente nas telenovelas brasileiras, com um naturalismo que difere do melodrama tradicional, os personagens, diante dos sofrimentos que experienciam e que são de certa forma sentidos "na pele" dos atores, são catalisadores de referentes de identificação com o espectador (MARTíN-BARBERO; MUÑOZ, 1992) - de classe, região, idade e de dramas, sentimentos, histórias de vida - que os tornam ainda mais significativos e relevantes para o público.

Trilhas sonoras, planos, iluminação, ritmos, figurinos, textos e o próprio encadeamento narrativo da trajetória do sofredor atuam nesse apelo à emoção catártica. Quando Cristiano (Celebridade, 2003) é apresentado ao público no capítulo 2, está sentado em uma mesa de bar cheia de garrafas vazias de cerveja. 0 primeiro plano no rosto do personagem enquadra, também, esses vestígios de que bebeu demais. Cristiano está cheio de olheiras, descabelado e com soluços de embriaguez. Seu filho Zeca, ainda criança, é quem o acompanha para cuidar do pai, servindo-lhe água e motivando o personagem a ficar sóbrio. A trilha que compõe o diálogo dos dois é de uma música instrumental lenta e triste, mas com sonoridade semelhante às músicas infantis. Teriam os papeis de pai e filho se invertido por conta do alcoolismo? Ao enquadrar o aperto de mãos carinhoso entre os dois, com as garrafas vazias ainda aparentes, o foco muda para outros dois personagens ao fundo que conversam, em tom de lamentação e compaixão, sobre a situação de Cristiano, com um diálogo que inicia com: “O Cristiano, coitado. É uma pena...”.

Esses seres sofredores, quase sempre enquadrados como dignos de pena e compaixão, quando não de desprezo e asco, tornam-se exemplares sob um ponto de vista moralizador, com os acontecimentos de suas vidas colocados sob o holofote para tornarem-se representativos de uma condição comum partilhada por muitos e, portanto, merecedoras de atenção (VAZ; RONY, 2011) - a exemplo da construção final da trajetória de sofrimento por dependência química de Mel (O Clone, 2001), ao completar um ano de sobriedade com uma reunião coletiva na clínica de reabilitação, em que amigos e familiares estão presentes. A música emocionante ao fundo, o primeiro plano da personagem intercalado com o plano aberto que mostra a alegria e a satisfação de todos os presentes, o enquadramento de Mel com sua mãe flagradas em um momento de 
carinho, de laços reestabelecidos, e depois a quebra da quarta parede, em que a personagem - em primeiro plano, primeiríssimo plano e plano detalhe na boca, nos olhos e nas mãos - dá ao público o seu depoimento emocionado de superação, de conquista da sobriedade, sobre o que perdeu pelo caminho, da luta diária que enfrenta e sobre o que conquistou e ainda sonha em conseguir. Mel partilha agora do mesmo grupo de pessoas anônimas e famosas mostradas ao longo da telenovela, com seus depoimentos de experiência e superação das drogas.

Para que essas imagens possam surtir algum efeito e construir significados, a piedade torna-se produto da maneira pela qual a televisão tece as relações emocionais entre espectadores e sofredores. “A piedade, portanto, chama a atenção para as operações de construção de significados pelos quais o sofredor é apresentado na tela, de modo a engajar o espectador em múltiplas formas de emoção e disposições para a ação” (CHOULIARAKI, 2008, p. 7, tradução nossa). Estar diante do sofrimento televisionado não implica, necessariamente, uma atitude contemplativa. A moralização do telespectador é construída de modo a compeli-lo à ação. Como exemplo, podemos citar o fato de que algumas histórias de sofrimento por drogadição em telenovelas motivaram, durante suas exibições, o compartilhamento de experiências tanto pelos próprios dependentes químicos quanto por seus familiares destes e a busca, na realidade, por ajuda para tratamento e cura. Isso sem falar no aumento da procura pelos grupos de ajuda na mesma época em que foram exibidas algumas dessas telenovelas, conforme mencionamos acima.

Nas narrativas ficcionais televisivas, o sofredor quase sempre atende a um padrão reconhecível: é o pobre, o infeliz, o miserável, o louco, o doente, o desviante (BIONDI, 2011), a mulher que apanha do marido, o idoso maltratado, o dependente químico, a pessoa com deficiência. Essa condição de sofrimento, principalmente na sua relação com o melodrama, tem o corpo como lugar privilegiado de revelação. É também por ele que os espectadores do sofrimento à distância são afetados sensivelmente e levados à comoção (BOLTANSKI, 2004; VAZ; RONY, 2011). Esses traços são ainda mais marcantes ao levarmos em conta os personagens dependentes químicos, que, em geral, quando estão num estágio avançado de compulsão e dependência, carregam em si aspectos físicos característicos: o abandono de si, a corporalidade repulsiva e a relação extrema com a droga (RUI apud LAGE, 2017). 
Se a vítima é capaz de emocionar os espectadores da trama, "é porque sua condição ganha corpo e visibilidade por meio da performance que oferece um modelo de sofrimento, [...] que dramatiza seu percurso de aflições e expressões truncadas até o ponto catártico em que finalmente é capaz de 'dizer tudo'” (XAVIER, 2000, p. 96). Nas telenovelas, essas catarses emocionais em geral se tornam cenas específicas e marcantes, seja pelo realismo, seja pelo investimento dramático das produções, como a cena em que Helena (Vale Tudo, 1988) volta a beber depois de uma desilusão amorosa e, em um bar sofisticado de hotel na Zona Sul carioca, fica bêbada, incomoda os outros clientes, briga com um desconhecido e faz um escândalo diante dos funcionários, quebrando objetos nas paredes, confrontando quem tenta controlá-la, gritando e, depois, aos prantos, é levada em uma camisa de força para uma nova internação em clínica.

É importante destacar que, nas telenovelas, a drogadição é majoritariamente abordada do ponto de vista do sofrimento, de modo a negligenciar as dimensões de prazer, satisfação e, até mesmo, os efeitos terapêuticos das drogas, por exemplo. Nas ficções telenovelísticas, o usuário é, na maior parte das vezes, a vítima sofredora, com a droga atuando como catalisadora de um sofrimento profundo e que questiona os valores morais dos que a consomem: o personagem sofre porque foi fraco e incapaz de resistir à tentação da droga. $\mathrm{E}$, em determinado momento da trama, atinge-se o "fundo do poço", a linha limítrofe do sofrimento que resulta na mudança da trajetória e do destino do personagem adicto. 0 ápice do sofrimento é, também, o gatilho moral rumo à redenção, à recuperação, à virada do personagem para a "direção certa", isto é, para uma vida sem drogas.

Nas telenovelas, as experiências da drogadição, fortemente associadas a dilemas morais, possibilitam construções dramáticas propícias à exploração das potencialidades fornecidas pelo melodrama: o sofrimento radical e encarnado no corpo, o drama familiar com suas repercussões para o círculo social em volta do personagem, as reviravoltas que compõem o arco dramático e a trajetória pessoal do personagem, a associação do consumo com a exploração da violência, o maniqueísmo que separa as boas pessoas dos usuários “maus", além do apelo sentimentalista.

O melodrama, enquanto espelho de uma consciência coletiva e elemento central na relação entre televisão e cultura (MARTíN-BARBERO, 2009), atua decisivamente na potencialização, popularização e abrangência social da telenovela. O sofrimento de vítimas, com as mais variadas motivações, é lugar comum nessas produções televisivas. 
No caso do sofrimento relacionado à drogadição, essas narrativas melodramáticas assumem contornos ainda mais intensos, expressivos, apelativos, legitimados por uma moralidade. Nessas narrativas ficcionais televisivas, o personagem adicto é obrigatoriamente colocado no lugar de exemplaridade com viés moral e pedagógico para mostrar representativamente os riscos, perigos e perdas a que estão sujeitos aqueles que se submetem às drogas, seguindo a característica dessas produções brasileiras de atuar com o merchandising social, compreendido como "um recurso comunicativo que consiste na veiculação em tramas e nos enredos [...] de mensagens socioeducativas explícitas, de conteúdo ficcional ou real” (LOPES, 2009).

A partir dessa síntese entre a linguagem televisiva, o matiz melodramático e o pânico moral em torno das drogas, o sofrimento associado à drogadição expressa sentimentos, produz sentidos e significados, interpela o público a acompanhar e a contemplar à distância não só pelo prazer voyeurístico, mas também pela própria possibilidade de certa purificação moral: o outro sofre desventuras trágicas porque se colocou nessa situação e/ou foi fraco demais para evitá-la. Desse modo, o personagem de alguma forma merece passar por tudo isso para apreender lições de vida. 0 melodrama nas telenovelas, quando associado às experiências de drogadição, adquire contornos que revelam a capacidade que a televisão tem de reelaborar, ressignificar, reconstruir sentidos e adaptar-se às transformações tecnológicas, culturais, sociais e econômicas da sociedade e do próprio dispositivo midiático, reiterando, assim, seu papel propício em manifestar tensões e conflitos.

Nosso trabalho faz parte de um esforço de reivindicar o valor, a legitimidade e o reconhecimento da televisão e da telenovela enquanto objetos de análise, considerando as próprias características e especificidades que compõem o meio. A despeito dos preconceitos e discursos que tentam deslegitimar a televisão enquanto campo de investigação e objeto empírico, pesquisas continuam a apontar a forte presença deste dispositivo midiático na vida cotidiana da sociedade. A teledramaturgia ainda atua como peça fundamental na construção dos hábitos de ver TV. Portanto, o papel cultural, social, político, econômico, tecnológico, moral das telenovelas no Brasil - e na América Latina - não pode nem deve ser negligenciado.

Ressaltamos, por último, as possibilidades abertas a partir desta investigação para outros pontos de reflexão e discussão mais aprofundadas, a exemplo das questões de gênero, classe e raça que envolvem a representação da dependência química nessas 
produções culturais midiáticas, buscando compreender razões pelas quais personagens femininas alçam maior destaque nas tramas e na memória coletiva e ainda as especificidades de experiências visuais e narrativas dadas a ver na abordagem dessa temática na ficção seriada televisiva, ambas mencionadas ao longo do nosso trabalho.

\section{REFERÊNCIAS}

ALMEIDA, Mariana. Telenovela, sofrimento e drogadição: construções estilísticas e narrativas em Vale Tudo, O Clone e Verdades Secretas. Dissertação (Mestrado em Comunicação, Linguagens e Cultura) Universidade da Amazônia, Belém, 2018.

ALMEIDA, Mariana. Experiências modernas de tempo na ficção seriada televisiva latino-americana: apontamentos iniciais a partir da minissérie Dois Irmãos. In: CONGRESSO BRASILEIRO DE CIÊNCIAS DA COMUNICAÇÃO, 42., 2019, Belém. Anais [...]. São Paulo: Intercom, 2019. Disponível em: http:// portalintercom.org.br/anais/nacional2019/resumos/R14-2243-1.pdf. Acesso em: 15 jan 2020.

APREA, Gustavo. La representación del sufrimiento: desde el melodrama clásico hasta las telenovelas posmodernas. San Antonio de los Baños: EICTV, 2011.

BACCEGA, Maria Aparecida. Narrativa ficcional de televisão: encontro com os temas sociais. Comunicação \& Educação, São Paulo, n. 26, p. 7-16, 2003.

BIONDI, Angie. O sofredor como exemplo no fotojornalismo: notas sobre o limite de uma identidade. Brazilian Journalism Research, Brasília, DF, v. 7, n. 1, p. 90-105, 2011.

BOLTANSKI, Luc. Distant suffering: morality, media and politics. Cambridge: Cambridge University Press, 2004.

CAMPOS, Edemilson Antunes de. Alcoolismo e identidade na teledramaturgia brasileira: o caso da telenovela Celebridade (2003). Comunicação, Política e Sociedade, São Paulo, v. 4, n. 1, p. 69-85, 2004.

CHOULIARAKI, Lilie. The mediation of suffering and the of cosmopolitan public. Television \& New Media, Thousand Oaks, v. 9, n. 5, p. 371-391, 2008. DOI 10.1177/1527476408315496.

CHOULIARAKI, Lilie. 011 de Setembro, a sua colocação em imagens e o sofrimento à distância. In: DAYAN, D. O terror espetáculo: terrorismo e televisão. Lisboa: Edições 70, 2009. p. 173-192.

CHOULIARAKI, Lilie. The ironic spectator: Solidarity in the age of post-humanitarianism. Malden: Polity Press, 2013.

FELDMAN, Ilana. 0 apelo realista. Revista Famecos, Porto Alegre, v. 15, n. 36, p. 61-68, 2008. DOI 10.15448/1980-3729.2008.36.4416. 
FRANÇA, Vera. A TV, a janela e a rua. In: FRANÇA, Vera. (org.). Narrativas televisivas: programas populares na TV. Belo Horizonte: Autêntica, 2006. p. 13-45.

GOMES, Itania Maria Mota. Gênero televisivo como categoria cultural: um lugar no centro do mapa das mediações de Jesús Martín-Barbero. Revista Famecos, v. 18, n. 1, p. 111-130, 2011. DOI 10.15448/1980-3729.2011.1.8801.

HAMBURGER, Esther. A expansão do feminino no espaço público brasileiro: novelas de televisão nas décadas de 1970 e 80. Estudos Feministas, Florianópolis, v. 15, n. 1, p. 153-175, 2007. DOI 10.1590/ S0104-026X2007000100010.

HAMBURGER, Esther. Telenovela e interpretações do Brasil. Lua Nova, São Paulo, v. 82, p. 61-86, 2011.

LAGE, Leandro Rodrigues. Testemunhos do sofrimento nas narrativas telejornalísticas: corpos abjetos, falas inaudíveis e as (in)justas medidas do comum. 2016. Tese (Doutorado em Comunicação Social) - Universidade Federal de Minas Gerais, Faculdade de Filosofia e Ciências Humanas, Belo Horizonte, 2016.

LAGE, Leandro Rodrigues. A produção da vítima na TV: o apelo à compaixão e a exemplaridade dos sofredores. Revista Contemporânea, Salvador, v. 15, n. 2, p. 655-675, 2017.

LOPES, Maria Immacolata Vassallo de. Telenovela brasileira: uma narrativa sobre a nação. Comunicação \& Educação, São Paulo, n. 26, p. 17-34, 2003. DOI 10.11606/issn.2316-9125.v0i26p17-34.

LOPES, Maria Immacolata Vassallo de. Telenovela como recurso comunicativo. MATRIZes, São Paulo, v. 3, n. 1, p. 21-47, 2009.

MARTÍN-BARBERO, Jesús. Dos meios às mediações: comunicação, cultura e hegemonia. 6. ed. Rio de Janeiro: Ed. UFRJ, 2009.

MARTÍN-BARBERO, Jesús. La telenovela em Colombia: televisión, melodrama y vida cotidiana. Diálogos de la Comunicación, Lima, n. 17, p. 44-60, 1987.

MARTÍN-BARBERO, Jesús; MUÑOZ, Sonia. Televisión y Melodrama: géneros y lecturas de la telenovela en Colombia. Bogotá: Tercer Mundo, 1992.

MARTÍN-BARBERO, Jesús; REY, German. Os exercícios do ver: hegemonia audiovisual e ficção televisiva. São Paulo: Editora Senac, 2001.

MOTTER, Maria Lourdes. O que a ficção pode fazer pela realidade? Jornal da USP, São Paulo, n. 599, p. 75-79, 2002.

OROZ, Silvia. Melodrama: o cinema de lágrimas na América Latina. 2. ed. Rio de Janeiro: Ed. Funarte, 1999. PALLOTTINI, Renata. Dramaturgia de televisão. São Paulo: Perspectiva, 2012. 
VAZ, Paulo; RONY, Gaelle. Políticas do sofrimento e as narrativas midiáticas de catástrofes naturais.

Revista Famecos, Porto Alegre, v. 18, n. 1, p. 212-234, 2011.

XAVIER, Ismail. Melodrama, ou a sedução da moral negociada. Novos Estudos, São Paulo, v. 2, n. 57, p. 81-90, 2000.

\section{NOTAS}

1 Trabalho produzido com o apoio da Coordenação de Aperfeiçoamento de Pessoal de Nível Superior (Capes), por meio de bolsa-taxa Prosup/Capes. Artigo desenvolvido no âmbito do projeto de pesquisa intitulado "Figurações da vulnerabilidade: linguagens do sofrimento, políticas do comum".

2 Os dados históricos são do Centro de Informações sobre Saúde e Álcool. Disponível em: http://www.cisa.org. br/artigo/234/historia-alcool.php. Acesso em: 17 abr. 2018.

3 Os dados sobre personagens dependentes químicos em telenovelas brasileiras não se encontra sistematizado de forma pública e completa, tendo sido o quadro elaborado e atualizado manualmente até ano de publicação deste artigo a partir de materiais diversos postados na internet e da memória de telespectador dos próprios autores.

Artigo recebido em: 14 de fevereiro de 2020 .

Artigo aceito em: 14 de setembro de 2020 . 